\title{
Formation of the approach to assess the effectiveness of project initiation for company development
}

\author{
Svetlana Belmas *, Nikolay Akatov, Sergey Kosyakin, and Sergey Belmas \\ Perm National Research Polytechnic University, 29 Komsomolsky Str., Perm, 614990, Russian Federation
}

\begin{abstract}
The paper presents the results of the assessment of the ability of a company to initiate and implement development projects. As a criterion for this ability, the authors propose a model for the assessment of the initiating impulse of changes. The authors propose the definition of this concept and present a model for its assessment based on a group of critical factors (willingness to act, responsibility, influence, faith and motives). A distinctive feature of the model is the proposal for a scheme for the formation of an impulse, which includes the stages of motivation, synthesis of activity and the formation of impulse itself. The paper presents a cognitive model and assesses the impulse formation depending on the value and significance of the measured critical factors.
\end{abstract}

\section{Introduction}

Many research works are devoted to the solution of the problems of the effectiveness improvement of strategic transformations of a company. It can be stated that this direction of research is a priority, since almost every research to some extent raises the issues of risks, feasibility, practicability and effectiveness of the implementation of strategies.

In this direction, the problem of the effectiveness of the initiation of development projects claims to act as the driving component of the problems of increasing the effectiveness of the strategic transformations of a company. Intuitively, each head of company agrees with the statement that the future fate of the project critically depends on the effectiveness of initiation. However, there are practically no rational criteria or models supporting this statement. At the same time, a detailed consideration of the initiation process itself, as the development of the conceived actions and the transition from the ideas to their realization, is manifested in the act of motivation or in the managerial impulse, which, both gains its strength and is transformed into ideas, or is lost, scattered, extinguished not reaching its goal.

The model of the initiating impulse of change (IIC) allows representing a wide range of possible results of the act of initiation and, accordingly, setting the requirements for management actions for its formation, taking into account the real complexity of this task, the level of uncertainty [1], the risk appetite of decisionmakers and the project team. For example, for the case of a high level of IIC certainty, this is a tough scenario of the development of events (unambiguous comprehensibility of project idea), a given time (speed) mode and specificity of goals. For a scenario case and a wide range of future scenarios it is scenario analysis, scenarios and scenario behavior. On the other hand, for complete uncertainty, the following aspects will be important: the power of vision, value models of behavior, trust, risk appetite of a group of key participants and other characteristics typical of specific situation. The attempts to give a definition of such a complex concept as IIC are faced with the problem of ambiguity of its perception. Thus, in scientific and practical sources, the impulse is defined as the effective exit of the stage of initiation by the leaders of an innovative project, which characterizes the positive (negative) perception of the project idea by staff and their willingness to implement the project.

Summarizing the results of the study on the problem of IIC determination, the following conclusions can be drawn: it is necessary to highlight the essential characteristics of the final result of initiation, determine the factors (circumstances) that characterize this result; give an opinion on the possibility of their assessment and propose a model to assess IIC, which allows the management of a company to analyze the initiation and purposeful synthesis of solutions for the increase the feasibility of their initiatives.

Using the proposed algorithm, the attention should be paid to the distinct initiative result which refers to the project management area. And it is the project concept that comes as the final result of the initiation process when making the decision on the project validity. At the same time, it is worth noting that this statement is justified for the classical management option. When we are dealing with projects of high complexity and those implemented under the conditions of high uncertainty, a reasonable result of initiation goes to an active subject of management. So the most important thing becomes choosing a leader of changes, getting support of toplevel leaders and creating conditions for the formation of an environment for team members' self-realization [2]. It is known from business practice that involved employees bring outstanding results for the company if they have

\footnotetext{
*Corresponding author: svetlana@rmc.edu.ru
} 
the right for their initiatives, as well as support and trust of their leaders and feel confidence in justified assessment of the project results.

This is how the management logic in the Agile approach is characterized, which sets a new perception of the project life cycle: Iterative Life Cycle, an approach that allows using feedback to refine and clarify work in progress [2].

It is necessary to note that the result of initiation, during the transition from the classical model to the postnon-classical model of management, from actions under the conditions of "recognizable future" to actions under the conditions of "complete uncertainty", is increasingly focused on the activation of subjectivity and the creation of an environment for self-development and selfrealization of active subjects of management, acting as the main guarantors of the feasibility of project. Thus, there are reasons to interpret the result of initiation as the creation of an organizational environment that provides the required level of strategic activity of management entities, manifested in their ability to form and maintain the required level of intensity of transformations in a company, set by the initiating impulse of changes.

The determination of the factors (circumstances) that characterize this result required the consideration of existing approaches to the solution of such problems. Thus, the study [3] presents the results of the assessment of the influence of a group of key aggregated factors (culture, organization, technology, information) on the readiness of a company for digital transformation. In the work [4], an attempt was made to assess the readiness of the IT department for digital business transformation by the development of a quantitative model to assess the level of the readiness of the IT department. There are existing approaches that use a comprehensive assessment of the readiness of a company, for example, using the EFQM 2020 model [5] in order to assess the ability of a company to implement development projects. In our opinion, the problem of the use of these approaches in order to determine the impulse characteristics of a company is in the fact that they focus more on the assessment of potential and to a lesser extent reflect the act of transforming initiatives and decision-makers into purposeful activities for the implementation of such initiatives.

For example, it is "a model for the assessment of the feasibility of a joint project in a network structure" [6] or "motivation to action" [7] with subsequent stages of its intensification. We made an attempt to form a model for the assessment of the impulse response, using a logical scheme for the formation of activity, which is based on "the five most important decision-making circumstances (readiness for action, responsibility, influence, faith and motives) and give the process either a powerful force or a paralyzing weakness" [7]. At the same time, the very act of impulse formation is considered in the form of three phases: motivation (managerial influence); the synthesis of activity (it includes the interaction of circumstances and the resolution of conflicts) and, in fact, the action, which is characterized by the resulting impulse.

\section{Formation of a model for the assessment of the resulting impulse based on the factors of its formation and their relationship}

Let us form a cognitive graph that takes into account the considered chains of cause-and-effect relationships leading to the result $[8,9,10]$. This graph in Figure 1 allows representing the formation of the result over time, depending on the level of influence of the leaders. The substantiation and calculation of the values of significant factors are presented below.

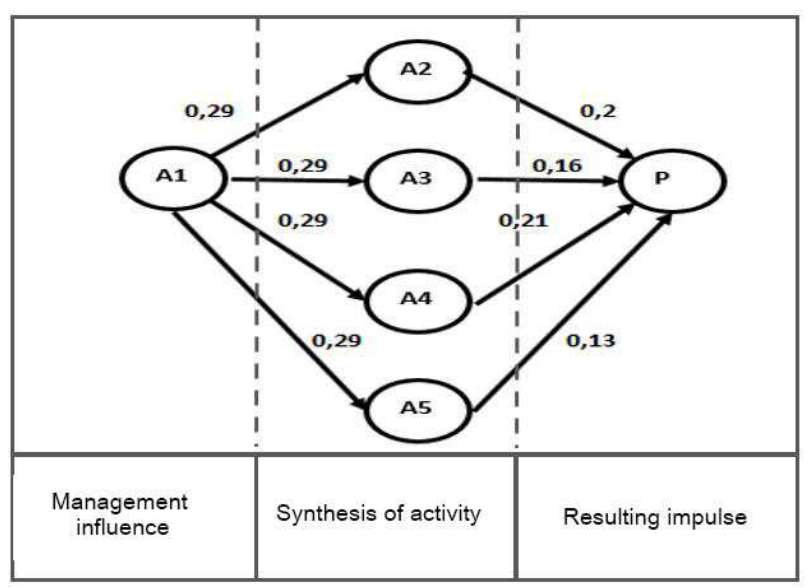

Figure 1. Graph showing the stages of the resulting impulse formation

The assessment of the actual value of the factors (circumstances) will be determined by a questionnaire survey of a group of experts of an enterprise.

Let us consider an approach related to the substantiation of the methodology, which is based on the results of processing field tests of the questionnaires presented below, with the purpose to find the value coefficients of one or another factor that determines the influence on the final result and analyze the cognitive model using these results.

An option of the questionnaire for interviewing experts is presented in Table. 1. The selected scale of expert assessments is from 1 to 5 , where 1 is the minimum value of the factor and 5 is the maximum value.

Tables 2-5 present the results of processed field tests questionnaires. A summary of the field tests is given in Table 2 and shows the process of the key result formation. This process assumes accumulating consolidated sum (column Y) for each expert based on his answers to the questionnaire, which ensures the formation of a matrix with data suitable for statistical calculations and factor analysis. 
Table 1. Questionnaire for expert survey

\begin{tabular}{|c|c|c|}
\hline \multirow[t]{2}{*}{ № } & \multicolumn{2}{|l|}{ Influence factor and its meaning } \\
\hline & The leaders' authority & $\mathbf{A}_{1}$ \\
\hline 1.1 & $\begin{array}{l}\text { Leaders take the position of a mentor and strive to } \\
\text { help and teach. They are always in a dialogue with } \\
\text { subordinates, they listen to them and consult them }\end{array}$ & \\
\hline 1.2 & $\begin{array}{l}\text { Leaders develop team spirit and dedication of } \\
\text { employees }\end{array}$ & \\
\hline 1.3 & $\begin{array}{l}\text { Leaders support group activity and provide } \\
\text { conditions for the generation and implementation of } \\
\text { useful ideas and solutions }\end{array}$ & \\
\hline & Level of trust & $\mathbf{A}_{2}$ \\
\hline 2.1 & $\begin{array}{l}\text { Established development goals of an enterprise are } \\
\text { considered as realistic, achievable and credible }\end{array}$ & \\
\hline 2.2 & $\begin{array}{l}\text { Full confidence in the fairness of distribution of the } \\
\text { results that will be obtained when the development } \\
\text { goals of an enterprise are achieved }\end{array}$ & \\
\hline 2.3 & $\begin{array}{l}\text { The attitude of employees of a company is } \\
\text { characterized by mutual trust, exchange of } \\
\text { experience and friendly relations }\end{array}$ & \\
\hline & Readiness to act & A3 \\
\hline 3.1 & $\begin{array}{l}\text { I have complete confidence in the feasibility of the } \\
\text { set goals and their achievement. }\end{array}$ & \\
\hline 3.2 & $\begin{array}{l}\text { I have all the necessary competencies in full for } \\
\text { productive activities, there is the possibility of their } \\
\text { development }\end{array}$ & \\
\hline 3.3 & $\begin{array}{l}\text { I have the necessary authority and the necessary } \\
\text { resources to work productively to achieve my goals }\end{array}$ & \\
\hline & Willingness to take responsibility & $\mathbf{A 4}$ \\
\hline 4.1 & $\begin{array}{l}\text { There is a real involvement of personnel in the } \\
\text { implementation of decisions for the development of } \\
\text { an enterprise and a willingness to take responsibility } \\
\text { for the consequences of decisions more than } \\
\text { provided by the current instructions }\end{array}$ & \\
\hline 4.2 & $\begin{array}{l}\text { Assignment of responsibility for the implementation } \\
\text { of projects of high complexity, as a rule, complies } \\
\text { with the personal interests of the subject of } \\
\text { management (project manager and team) }\end{array}$ & \\
\hline 4.3 & $\begin{array}{l}\text { Experience, values, positions of managers and } \\
\text { mechanisms that form confidence in the objectivity } \\
\text { and fairness of decisions in case of unfavorable } \\
\text { outcomes }\end{array}$ & \\
\hline & Level of motivation & A5 \\
\hline 5.1 & $\begin{array}{l}\text { A company has a common understanding and the } \\
\text { same interpretation of the standards and regulations } \\
\text { laid in the basis of motivation and performance }\end{array}$ & \\
\hline 5.2 & $\begin{array}{l}\text { The accepted norms and rates of remuneration are } \\
\text { fully justified and fair }\end{array}$ & \\
\hline 5.3 & $\begin{array}{l}\text { A company has motivational provisions (incentives) } \\
\text { that encourage the search for innovative solutions } \\
\text { and their implementation }\end{array}$ & \\
\hline
\end{tabular}

To create a multiple regression model, the Regression program was used, which was connected to the numerical editor MS Excel. Filling out the "Regression" form with initial data assumes:

- the description of the input interval Y (indicating the range of cells in column $\mathrm{Y}$ of Table 2)

- the description of the input interval $X$ (indicating the range of cells in columns A1-A5 of Table 2)

- the description of the report output parameters (indication of the cell from which the report starts).

Figure 2 shows the results of the regression analysis. For each of the factors, the coefficients A_ (i) were found, the Student and Fisher tests were carried out and the regression statistics were calculated [11].

Table 2. Formation of a key result

\begin{tabular}{|c|c|c|c|c|c|c|}
\hline Y & A1 & A2 & A3 & A4 & A5 & № \\
\hline 14 & 2 & 2 & 5 & 3 & 2 & expert №1 \\
\hline 15 & 2 & 2 & 2 & 4 & 5 & expert №2 \\
\hline 18 & 3 & 2 & 3 & 5 & 5 & expert №3 \\
\hline 15 & 1 & 5 & 2 & 3 & 4 & expert №4 \\
\hline 17 & 3 & 3 & 4 & 4 & 3 & expert №5 \\
\hline 18 & 5 & 4 & 5 & 2 & 2 & expert №6 \\
\hline 17 & 5 & 1 & 2 & 4 & 5 & expert №7 \\
\hline 18 & 5 & 2 & 2 & 5 & 4 & expert №8 \\
\hline 15 & 2 & 5 & 3 & 1 & 4 & expert №9 \\
\hline 19 & 5 & 3 & 5 & 3 & 3 & expert №10 \\
\hline 16 & 4 & 2 & 2 & 4 & 4 & expert №11 \\
\hline 11 & 3 & 1 & 1 & 3 & 3 & expert №12 \\
\hline 10 & 2 & 2 & 1 & 2 & 3 & expert №13 \\
\hline 20 & 5 & 3 & 3 & 5 & 4 & expert №14 \\
\hline 16 & 5 & 3 & 1 & 4 & 3 & expert №15 \\
\hline 12 & 3 & 1 & 4 & 3 & 1 & expert №16 \\
\hline 15 & 3 & 4 & 3 & 1 & 4 & expert №17 \\
\hline 14 & 3 & 2 & 4 & 4 & 1 & expert №18 \\
\hline 14 & 4 & 2 & 1 & 3 & 4 & expert №19 \\
\hline 20 & 4 & 5 & 3 & 4 & 4 & expert №20 \\
\hline 14 & 2 & 1 & 3 & 4 & 4 & expert №21 \\
\hline 19 & 5 & 3 & 3 & 5 & 3 & expert №22 \\
\hline 14 & 4 & 2 & 2 & 3 & 3 & expert №23 \\
\hline
\end{tabular}

From the data in Figure 2, it follows that, according to Student's test, all coefficients are significant (column $\mathrm{p}$ - the value contains data equal to 0 , which is less than the 0.05 level). According to Fisher's test (the second table, column "Significance F"), we can conclude that the model is generally adequate and reliable with a probability of 0.95 (the significance of $F$ is zero, which is less than the 0.05 level). The correlation analysis (the first table) shows that the static relationship between the key result and the explanatory factors are very strong (normalized $\mathrm{R}^{2}=1$, which is greater than the level of $0.7)$.

Thus, we can conclude that the model is adequate and suitable for further calculations.

Consequently, the hypothesis about the correctness of the formation of the result $Y_{i}=\sum_{j=1}^{5} A_{i, j}$ has a solid confirmation, and the coefficients of the model are $A_{i}=$ $1, i=\overline{1-5}, ; A_{0}=0$ (column coefficients of the third table of Figure 2).

The next step as the method proceeds to the correlation analysis, the aim being to exclude collinear factors from the model and this principle goes as follows [11]:

- if two variables $x_{i}, x_{j}$ are clearly collinear (correlation coefficient $R_{x i, x j}>0.7$ ), then we exclude one of them;

- we include the factor that has the least tightness of connection with other factors;

- the closer to 1 the determinant of the crossfactorial correlation matrix, the less the multicollinearity of the factors. 


\begin{tabular}{|c|c|c|c|c|c|}
\hline \multicolumn{2}{|l|}{ Conclusion of the results } & & & & \\
\hline \multicolumn{2}{|c|}{ Regression statistics } & & & & \\
\hline Multiple R & 1 & & & & \\
\hline R-square & 1 & & & & \\
\hline Normalized R-square & 1 & $>0.7$ & & & \\
\hline Standard error & $6.2384 \mathrm{E}-16$ & & & & \\
\hline Observations & 23 & & & & \\
\hline \multicolumn{6}{|l|}{ analysis of variance } \\
\hline & $d f$ & ss & MS & $F$ & value $F$ \\
\hline Regression & 5 & 162.869565 & 32.57391 & $8.37 E+31$ & $3.42 E-266$ \\
\hline \multirow{3}{*}{$\begin{array}{l}\text { Excess } \\
\text { Total }\end{array}$} & 17 & $6.616 \mathrm{E}-30$ & $3.89 \mathrm{E}-31$ & & $<0.05$ \\
\hline & 22 & 162.869565 & & & \\
\hline & Coefficient & $\begin{array}{l}\text { Standard } \\
\text { error }\end{array}$ & t-stat & $p$-value & \\
\hline A0 & $-2.6645 \mathrm{E}-15$ & $8.1941 E-16$ & -3.25178 & 0.004694 & \\
\hline A 1 & 1 & $1.139 \mathrm{E}-16$ & $8.78 E+15$ & 5E-262 & \\
\hline A 2 & 1 & $1.2079 \mathrm{E}-16$ & $8.28 E+15$ & $1 E-261$ & \multirow{4}{*}{$<0.05$} \\
\hline A 3 & 1 & $1.2511 \mathrm{E}-16$ & $7.99 \mathrm{E}+15$ & $2 E-261$ & \\
\hline A 4 & 1 & $1,3924 \mathrm{E}-16$ & $7.18 \mathrm{E}+15$ & $2 E-260$ & \\
\hline A5 & 1 & $1.4732 \mathrm{E}-16$ & $6.79 \mathrm{E}+15$ & $4 E-260$ & \\
\hline
\end{tabular}

Figure 2. Regression Analysis Report

In order to calculate the cross-correlation matrix, in the numerical editor MS Excel, we should use the program "Correlation". Filling out the correlation form with initial data assumes:

- the description of the input data (indicating the range of cells of all columns, starting from 1, column Y to 24 of column A5 in Table 3),

- the description of the report output parameters (indication of the cell from which the report starts).

The report on the values of the coefficients of crosscorrelation $(\mathrm{R})$ is shown in Table 3

Table 3. Cross-correlation coefficient values (R)

\begin{tabular}{|c|r|r|r|r|r|r|}
\hline & \multicolumn{1}{|c|}{$Y$} & \multicolumn{1}{c|}{$A 1$} & \multicolumn{1}{c|}{$A 2$} & \multicolumn{1}{c|}{$A 3$} & \multicolumn{1}{c|}{$A 4$} & \multicolumn{1}{c|}{$A 5$} \\
\hline$Y$ & 1 & 0.62 & 0.4 & 0.34 & 0.48 & 0.32 \\
\hline$A 1$ & 0.62 & 1 & -0.04 & 0.03 & 0.37 & -0.01 \\
\hline$A 2$ & 0.43 & -0.04 & 1 & 0.19 & -0.34 & 0.11 \\
\hline$A 3$ & 0.34 & 0.03 & 0.19 & 1 & -0.08 & -0.47 \\
\hline$A 4$ & 0.48 & 0.37 & -0.34 & -0.08 & 1 & 0.21 \\
\hline$A 5$ & 0.32 & -0.01 & 0.11 & -0.47 & 0.21 & 1 \\
\hline
\end{tabular}

The determinant of the cross-factorial correlation matrix can be found using the built-in function = MDETERM (), argument being the range of cells of the explanatory factors. Its value in this case is 0.66 , that is slightly less than the 0.7 level. The fact itself testifies the practical absence of collinear factors in the model and suggests ceasing the procedure to further selection of explanatory factors.

In order to determine the value influence of the explanatory factors on the result the following formula is applied as a problem solution:

$$
\Delta_{j}=\frac{A_{j} S(A J) R_{Y A J}}{S(y) R}
$$

where $A_{i}$ - regression model coefficients (Figure 1 Table $3 A_{i}=1, i=\overline{1-5}$ ),

$S\left(x_{i}\right)$ - standard deviation of the factor $x_{i}$ - can be found using the data in Table 3 and the function = STDEV(),

$R_{Y X i}$ - the correlation coefficient of the factor $x_{i}$ with the main result y (Table 4$)$,

$\Delta_{i}$-contribution (value) of explanatory factors to the key result
The results of the calculation of the values of the value coefficients of significant factors are shown in Tables 4. Table 5 shows the results of cognitive modeling.

Table 4. The values of the coefficients of significant factors

\begin{tabular}{|r|r|r|r|r|r|r|}
\hline & \multicolumn{1}{|c|}{$Y$} & \multicolumn{1}{|c|}{$A 1$} & \multicolumn{1}{c|}{$A 2$} & \multicolumn{1}{c|}{$A 3$} & \multicolumn{1}{c|}{$A 4$} & \multicolumn{1}{c|}{$A 5$} \\
\hline$A_{j}$ & & 1 & 1 & 1 & 1 & 1 \\
\hline$R$ & 1 & 0.62 & 0.43 & 0.34 & 0.48 & 0.32 \\
\hline$S$ & 2,72 & 1.27 & 1.26 & 1.27 & 1.16 & 1.11 \\
\hline$\Delta_{j}$ & & 0.29 & 0.20 & 0.16 & 0.20 & 0.13 \\
\hline \multicolumn{6}{|c|}{ Total: $\sum_{j=1}^{5} \Delta_{j}}$, & 1 \\
\hline
\end{tabular}

Table 5. The calculation results for a strong level of a leader's authority

\begin{tabular}{|c|c|c|c|c|c|c|}
\hline & 0 & 1 & 2 & 3 & 4 & 5 \\
\hline $1^{A}$ & 4.5 & 4.5 & 4.5 & 4.5 & 4.5 & 4.5 \\
\hline $2^{A}$ & 0 & 1.30 & 2.61 & 3.92 & 5 & 5 \\
\hline $3^{A}$ & 0 & 1.30 & 2.61 & 3.92 & 5 & 5 \\
\hline $4^{A}$ & 0 & 1.30 & 2.61 & 3.92 & 5 & 5 \\
\hline $5^{A}$ & 0 & 1.30 & 2.61 & 3.92 & 5 & 5 \\
\hline$P$ & 0 & 0 & 1.85 & 2.78 & 3.54 & 3.54 \\
\hline
\end{tabular}

Similar calculations were performed for a low and medium level of the leader's authority, which allowed creating the dependencies shown in Figure 3.

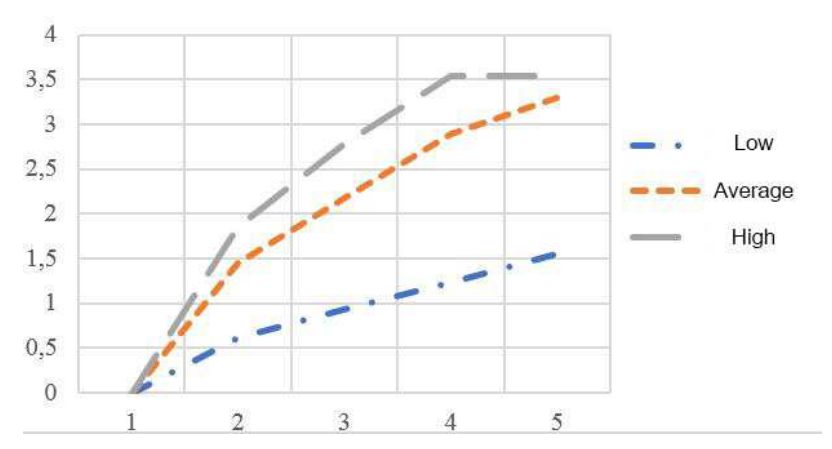

Figure 3. The behavior of the resulting impulse depending on the factor "the leaders' authority"

The results of the calculations made allow to illustrate the rate of change in the transient processes of the formation of stable results of the estimated resultant pulse (on the front edge of the pulse):

- the achieved level of the resulting impulse significantly depends on the assessment of the level and significance of the priority factors of the stimulation of the subjects of activity to proactive behavior and the implementation of purposeful actions;

- the sustainable results with a strong level of influence of managers are achieved $20 \%$ faster compared to the average level of influence and more than 2 times compared to a weak level; 
- the formation of primary sustainable results with a strong level of influence of managers increases the level of results by $22 \%$ compared to the average level and 2.9 times higher compared to the low level.

\section{Conclusion}

This research confirms the practicability of using the initiating impulse of changes approach which proved its efficiency during assessment of initiating development projects in the company.

At the same time, focusing attention on the sequence of formation of the resulting impulse allows the management of a company to make targeted decisions to accelerate the transition from the formation of models and judgments on activities, directly to activities in order to achieve the result.

The presented method allows obtaining a visual representation of the rate of change of transient processes in the formation of the resulting impulse, depending on the value and significance of the key influencing factors. On the other hand, with a relatively simple procedure for the assessment of factors, it is possible to update quickly the assessment questionnaires, clarify the structure of key factors and the final assessments of impulse characteristics.

The proposed model for the evaluation of the initiating impulse of changes can be used as the basis for the assessment the willingness of a company to initiate development projects. The essence of which is to assess the organizational readiness of a company based on the identification of its ability to create and maintain an initiating impulse of changes necessary for the implementation of projects of various levels of complexity and uncertainty.

\section{References}

1. H. Courtney, J. Kirkland, P. Vigerio, McKinsey Herald: Management Theory and Practice, 1, 6881 (2002)

2. Project Management Institute, Agile: practical guide, Retrieved from: www.PMI.org

3. M. Gill, S. VanBoskirk, The Digital Maturity Model 4.0. Benchmarks: Digital business transformation playbook (2016),

4. E. A. Isaev, N.L. Korovkina, Business Informatics, 2 (44) (2018)

5. F. A. Meyer Radarise your business for success: EFQM (Brussels Representative Office, 2005)

6. M.M. Gakashev, Regional Economics and Management: Electronic Scientific Journal, 4, 20-31 (2017)

7. A. G. Teslinov, Manage Decisions: How to Think, to Decide and to Act. (Moscow: FLINT, 2021)

8. V. V. Davnis, V.I. Tinyakova, Predictive Models of Expert Preferences, (Voronezh: Publishing House of Voronezh state universityб 2005)

9. O. N. Luchko, V.A. Marenko, Educational Technologies, 1, 69-75 (2015)
10. Akatov N.B., Kosyakin S.I., Bulletin of Perm National Research Polytechnic University: Socioeconomic Sciences, 3, 109-124 (2019) 